\title{
BMJ Open A police education programme to integrate occupational safety and HIV prevention: protocol for a modified stepped-wedge study design with parallel prospective cohorts to assess behavioural outcomes
}

\author{
Steffanie A Strathdee, ${ }^{1}$ Jaime Arredondo, ${ }^{1}$ Teresita Rocha, ${ }^{1}$ Daniela Abramovitz, ${ }^{1}$ \\ Maria Luisa Rolon, ${ }^{1,2}$ Efrain Patiño Mandujano, ${ }^{2}$ Maria Gudelia Rangel, ${ }^{3}$ \\ Horcasitas Omar Olivarria, ${ }^{4}$ Tommi Gaines, ${ }^{1}$ Thomas L Patterson, ${ }^{1}$ Leo Beletsky ${ }^{1,5}$
}

To cite: Strathdee SA, Arredondo J, Rocha T, et al. A police education programme to integrate occupational safety and HIV prevention: protocol for a modified stepped-wedge study design with parallel prospective cohorts to assess behavioural outcomes. BMJ Open 2015;5:e008958. doi:10.1136/bmjopen-2015008958

- Prepublication history and additional material is available. To view please visit the journal (http://dx.doi.org/ 10.1136/bmjopen-2015008958).

Received 1 June 2015 Accepted 25 June 2015

CrossMark

For numbered affiliations see end of article.

Correspondence to Dr Steffanie A Strathdee; sstrathdee@ucsd.edu

\section{ABSTRACT}

Introduction: Policing practices are key drivers of HIV among people who inject drugs (PWID). This paper describes the protocol for the first study to prospectively examine the impact of a police education programme (PEP) to align law enforcement and HIV prevention. PEPs incorporating HIV prevention (including harm reduction programmes like syringe exchange) have been successfully piloted in several countries but were limited to brief pre-post assessments; the impact of PEPs on policing behaviours and occupational safety is unknown.

Objectives: Proyecto ESCUDO (SHIELD) aims to evaluate the efficacy of the PEP on uptake of occupational safety procedures, as assessed through the incidence of needle stick injuries (NSIs) (primary outcome) and changes in knowledge of transmission, prevention and treatment of HIV and viral hepatitis; attitudes towards PWID, adverse behaviours that interfere with HIV prevention and protective behaviours (secondary outcomes).

Methods/analysis: ESCUDO is a hybrid type I design that simultaneously tests an intervention and an implementation strategy. Using a modified steppedwedge design involving all active duty street-level police officers in Tijuana ( $\mathrm{N}=\sim 1200$ ), we will administer one $3 \mathrm{~h}$ PEP course to groups of 20-50 officers until the entire force is trained. NSI incidence and geocoded arrest data will be assessed from department-wide de-identified data. Of the consenting police officers, a subcohort $(\mathrm{N}=500)$ will be randomly sampled from each class to undergo pre-PEP and post-PEP surveys with a semiannual follow-up for 2 years to assess self-reported NSIs, attitudes and behaviour changes. The impact on PWIDs will be externally validated through a parallel cohort of Tijuana PWIDs.

Ethics/dissemination: Research ethics approval was obtained from the USA and Mexico. Findings will be
Strengths and limitations of this study

Proyecto ESCUDO is one of the few interventions attempting to alter the law enforcement environment for infectious disease transmission, and the first study to prospectively examine the impact of a police education programme (PEP) to align law enforcement and HIV prevention.

- Although our study design precludes randomising officers to receive the training, our use of a modified stepped wedge design is novel and ideally suited for cases like ours when an intervention is presumed to do more good than harm, it is logistically impractical to offer the intervention simultaneously to all participants, and the study outcomes do not require an overly long follow-up.

- Our use of geocoded arrest data obtained through our collaboration with the Tijuana police will allow us to objectively determine the extent to which the PEP is associated with changing arrest patterns.

disseminated through open access to protocol materials through the Law Enforcement and HIV Network.

Trial registration number: NCT02444403.

\section{BACKGROUND}

People who inject drugs (PWID) account for $30 \%$ of the world's infections with HIV outside of sub-Saharan Africa ${ }^{1}$ among whom prevalence of hepatitis $\mathrm{B}$ and hepatitis $\mathrm{C}$ virus (HCV) often exceeds $80 \% .^{2}$ Among PWID, policing practices are among the most 
potent and pervasive risk factors linked to the risk of acquiring HIV and other blood-borne infections, with documented examples from Ukraine, Russia, Vietnam, Thailand, the USA, Canada and Mexico. ${ }^{3-9}$ In particular, arrests for drug possession, soliciting bribes and unlawful confiscation of syringes can influence where, with whom, when and how PWIDs consume drugs. Policing practices can directly affect PWID by discouraging them from carrying their injection equipment or injecting hurriedly in the street, in shooting galleries (where used needles are rented or sold), or by injecting in less visible -and higher risk-sites on their body, and seeking out 'hit doctors' who help them inject drugs. In these situations, PWID are at higher risk of acquiring HIV and other blood-borne infections such as viral hepatitis ${ }^{3} 1011$ or overdose mortality. ${ }^{12}$

Policing practices can also indirectly increase PWIDs' vulnerability to blood-borne infections by discouraging their use of prevention and treatment services. For example, syringe exchange programmes (SEPs) and opioid substitution treatment (OST) can significantly reduce HIV incidence among PWID by reducing the risk of needle sharing, but police often undermine their impact by harassing programme staff and discouraging PWID from transporting syringes, utilising SEPs and OST, ${ }^{13-22}$ or displacing vulnerable individuals to areas with limited access to these services. ${ }^{3} 111218$ 23-30

Previous research by our team has shown that these policing practices are highly prevalent in Mexico-US border cities, such as Tijuana (adjacent from San Diego, California, USA) and Ciudad Juárez (adjacent from El Paso, Texas), which are both hotspots for drug use. Although it is legal to carry syringes without a prescription in Mexico, half of the PWID living in the northern border cities of Tijuana and Ciudad Juárez report syringe confiscation by police, ${ }^{5}{ }^{6}$ which is independently associated with PWID reports of receptive needle sharing, ${ }^{5}$ injecting in shooting galleries, ${ }^{31}$ seeking injection assistance by 'hit doctors' ${ }^{28}$ and a higher prevalence of HIV infection. ${ }^{6}$ In Tijuana, PWID attending SEPs and OST frequently report police harassment and bribes. ${ }^{32}{ }^{33}$ Interventions which attempt to promote HIV risk reduction among PWID are likely to have limited effectiveness in the face of such pervasive structural barriers. In many settings, legal measures intended to improve the alignment of police practices and public health objectives (such as authorising SEPs, decriminalising syringe or drug possession, or creating special enforcement carve-outs around harm reduction programmes) have demonstrated limited benefit because of the gaps between policies as written and their street-level implementation. ${ }^{34-37}$

In an effort to reduce or eliminate policing practices that heighten PWIDs' vulnerability to HIV and other blood-borne infections, international efforts by researchers, non-governmental organisations, health advocacy organisations and the United Nations Office on Drug Control emphasise the need to implement police education programmes that harmonise policing practices with public health. Previous research suggests that police are receptive to education on working with at-risk groups when 'bundled' with occupational safety messages that highlight their own risk of acquiring HIV and viral hepatitis through needle stick injuries (NSI). ${ }^{38} 39$ Police experience an elevated risk of NSI emanating from routine contact with PWID, which can lead to infectious disease acquisition. Although the risk of acquiring HIV from NSI is low, ${ }^{40}$ risks of acquiring hepatitis $\mathrm{B}$ and $\mathrm{C}$ are considerable given their much higher prevalence and infectiousness. Moreover, police concerns about acquiring infectious disease through contact with PWID often exaggerate the actual risk, contributing to workplace stress and officer hostility towards drug users. $^{14}$

In Tijuana, the risk of police acquiring blood-borne infections through an occupational NSI may be higher due to frequent altercations with PWID during 'operativos' (police sweeps), and since an estimated $40 \%$ of Tijuana PWID use high dead-space syringes ${ }^{41}$ that retain 1000 times more blood than low dead-space syringes ${ }^{42}$ and can still transmit HCV after 60 days. ${ }^{43}{ }^{44}$ Further, the risk of NSIs among police across Mexico may be elevated since Mexico's recent drug policy reform that allows citizens to carry specified amounts of drugs for personal possession leads some police to handle used syringes to determine whether drug possession exceeds the legal limits. Mistrust and lack of clarity about syringe possession laws discourages PWID from offering up syringes during police encounters, elevating officers' risk of accidental NSI. ${ }^{45}$

On-duty NSIs are very anxiety-provoking for police officers. ${ }^{45-47}$ Among 803 police officers in San Diego, California, USA, $83 \%$ felt that on-duty NSI posed the same magnitude of risk as a gunshot wound; $29.6 \%$ had ever an NSI, of whom $27.7 \%$ had repeat NSIs. Correlates of NSI were inexperience, working the evening shift and conducting pat-down searches. ${ }^{46}$ In Tijuana, more than $15 \%$ of Tijuana police officers responding to an anonymous survey in 2014 reported ever having had an NSI. ${ }^{48}$ Although the incidence of NSIs in Tijuana is unknown, estimates of NSI incidence per 10000 exposures among police varies globally from 68 in Amsterdam, ${ }^{49} 50 \quad 44.1$ in Rhode Island, ${ }^{51} 38.7$ in New York City ${ }^{52}$ and 36 in North Carolina. ${ }^{50}$

Police education programmes (PEPs) linking HIV prevention and harm reduction content with police occupational safety information have been successfully piloted in the USA and Kyrgyzstan, but evaluations were limited to brief pre-post assessments of police knowledge, attitudes and intentions. ${ }^{78}$ The impact of PEPs on policing behaviours, uptake of occupational safety measures and NSI incidence remains unknown. Police departments are unlikely to sustainably institutionalise PEPs unless persuaded that integrating HIV prevention into their curricula will protect officers' health and is cost-effective. PEPs represent a promising structural intervention to harmonise law enforcement 
and public health efforts to reduce transmission of HIV and related infections in countries with high burdens of drug use and blood-borne infections. Empirical evidence is lacking, however, to persuade police officers and departments and policymakers that they are worthy of scale-up. Our study is designed to address this critical gap, based on a novel partnership with the Tijuana police department.

\section{METHODS}

\section{Description of the Tijuana police force}

The Tijuana police department is among Mexico's largest municipal police forces, with $\sim 2000$ police officers (1.38 per 1000 inhabitants), ${ }^{53} 54$ of whom approximately 1200 actively work on the street across 15 precincts. The mean age is 35 years, $80 \%$ are male and $>75 \%$ are below age $40 .{ }^{54} 55$ Employment requirements include a high school degree, being aged $\geq 18$ and passing required toxicological and polygraph examinations. Police salaries range from US $\$ 1000-$ US $\$ 2000$ per month, depending on rank. Since 2007, the mean annual turnover (eg, quitting, termination, moves, retirements) is $6.2 \% .^{54}$ By federal, state and local policy, all officers are subject to annual training requirements, including periodic refresher training modules.

\section{Research collaboration between UCSD and the Tijuana police department}

In 2013, Tijuana's Chief of Police signed a memorandum of understanding (MOU) with our binational team, through which we agreed to develop and implement a PEP focused on occupational safety and HIV prevention, and an NSI response and surveillance system for the entire force. The police department agreed to provide our team with de-identified data on NSI incidence and geocoded arrest data. This agreement was upheld by the Municipal Police Chief's subsequently elected replacement, as well as the new Tijuana's mayor who assumed their duties in December 2013. In fact, the Tijuana mayor mandated the PEP for all of the city's police officers.

The Tijuana police department and our study team agreed to the following terms that would promote the sustainability of the PEP following its evaluation, reduce the burden on police officers and administrative staff, and engender trust. First, we agreed that the PEP would be integrated into the existing refresher training schedule for Tijuana police officers. Second, the PEP would be developed by our study team in collaboration with the Director of the municipal police academy (Instituto de Capacitacion y Adiestramiento Profesional de Tijuana (ICAP)), the Head of Planning and Strategic Projects at the Tijuana Police Department and their key Statistics staff. Third, our team would train the police academy instructors on the elements of the PEP, and they in turn would train their officers (ie, 'train the trainer' model). Fourth, we agreed to document costs of the programme and later conduct a cost-effectiveness analysis that would be shared with the police department and police academy leadership.

The resulting PEP and its evaluation component have been titled Proyecto ESCUDO (Project SHIELD). This project has the following aims: (1) To evaluate the efficacy of the PEP on uptake of occupational safety procedures, as assessed through the incidence of occupational NSI (primary outcome), monitored by a departmentwide NSI surveillance programme, and self-reported NSI; (2) To evaluate the efficacy of the PEP on changes in the following secondary outcomes: (1) knowledge of transmission, prevention and treatment of HIV and related infections (sexually transmitted infections and viral hepatitis); (2) attitudes towards PWID; (3) adverse behaviours that interfere with HIV prevention (ie, arrests near SEP and drug treatment locations); (4) protective behaviours (eg, use of barrier protection, selfreported reductions in syringe confiscation). (3) To assess potential mediating and moderating factors that influence PEP efficacy, including changes in knowledge and attitudinal factors and occupational constructs. We hypothesise that, over the course of the 24-month follow-up, the PEP will be associated with significant declines in NSI incidence, improved knowledge of HIV and related infections, uptake of occupational safety measures and decreases in behaviours that undermine HIV prevention (eg, syringe confiscation, police harassment of PWID at OST and SEPs).

\section{Hypotheses}

H1. The PEP will be associated with a significant decline in NSI incidence among the force during follow-up.

H2.1. The PEP will be associated with significantly increased knowledge of transmission, prevention and treatment of HIV and HCV among Tijuana police officers participating in the subcohort.

H2.2. The PEP will be associated with significant improvements in attitudes towards PWID, sex workers and HIV-infected persons.

H2.3. The PEP will be associated with significantly fewer reports of syringe confiscation by police officers.

H2.4. The PEP will be associated with a lower incidence of arrests near SEP and drug treatment locations.

H2.5 The PEP will be associated with the increased use of barrier protection during pat-downs and arrests.

H2.6. The PEP will be associated with increased knowledge about the narcomenudeo drug policy reform.

H3.1 The impact of PEP on NSI incidence and adverse and protective behaviours will be moderated by officers' motivation to undergo the training, years in the force and autonomous support received from supervisors. 


\section{Conceptual framework of the PEP}

The transcontextual Model (TCM) has been successfully used to evaluate injury prevention PEPs in international settings. ${ }^{56}$ We applied the TCM to conceptualise and assess mechanisms through which the PEP can impact occupational safety and officers' behaviours. This model incorporates key theoretical constructs from selfdetermination theory (SDT) ${ }^{57}$ and the theory of planned behaviour (TPB). ${ }^{58}$ TPB emphasises the role of psychosocial factors in affecting decision-making processes that translate to changes in behaviour. Herein, such factors include trainee attitudes, subjective norms, self-efficacy and intentions (see figure 1). These ТРВ constructs have had robust predictive value in the realm of injury prevention. ${ }^{59} 60$ SDT highlights the role of motivation and perceived autonomy as 'regulators' that may mediate the impact of training initiatives on trainee practices and adherence. Perceived support by supervisors (autonomy support) for injury prevention ${ }^{61}$ and motivation to participate in an educational intervention are known antecedents for change in behavioural and corollary end points. ${ }^{62}$ Validated in the realm of occupational safety and injury prevention, ${ }^{6364}$ TCM is based on the complex interplay between SDT and TPB factors in shaping the impact of educational interventions. ${ }^{56}$ The TCM model also suggests that changes in self-efficacy produced by training can be transferred to domains that are related but do not serve as the focus of the training intervention. ${ }^{56}$ Herein, TCM elucidates the pathways through which the PEP may shift ancillary police activities, including adherence to departmental procedures and drug policies (eg, targeting PWID for enforcement activities as they seek to access SEPs or OST). These shifts may improve police occupational safety by reducing the prevalence of adverse encounters with PWID, but they may also have collateral population health benefits such as reducing risk behaviour and infectious disease incidence among PWID. TCM has been widely used in the context of physical education training, ${ }^{65-68}$ and research on police occupational health, but its use in the assessment of a PEP focused on NSI prevention is innovative. ${ }^{56}$

\section{PEP intervention}

On the basis of best practices established by Beletsky et $a l^{38} 396970$ and with active input from ICAP instructional experts, we culturally and linguistically adapted existing PEP materials that bundle occupational safety information with content addressing the legal, scientific and logistical underpinnings of HIV prevention. Through train-the-trainer workshops, we prepared ICAP instructors by building knowledge, pedagogical skills and capacity, with an emphasis on a peer-to-peer perspective to maximise uptake. ${ }^{70}$ An initial team of three trained ICAP instructors will deliver the standardised curriculum through slide-assisted oral presentations in $1 \mathrm{~h}$ sections (ie, modules), offered consecutively in a single session. The entire training lasts approximately $31 / 2$ hours.

Module I covers basic epidemiology, prevention and treatment of HIV, viral hepatitis and STIs, safe syringe disposal and fundamentals of addiction. This content is delivered within the framework of police occupational safety. Postexposure protocols and appropriate follow-up procedures are outlined, including the NSI response sequence. Lecture material is reinforced with a video vignette explaining key NSI prevention and the NSI response protocol.

Module II covers key provisions of Mexico's national drug policy (ley de narcomenudeó, which defines amounts of drugs allowed for personal possession), as well as other legal provisions pertinent to HIV prevention, including the legality of syringe and condom possession. To shift attitudes, rationales for public health-based laws targeting at-risk groups are discussed and implications for police practice are outlined. Connections between police occupational safety and public health-oriented drug laws are reinforced through a video that re-enacts a scene where a police officer is shown performing appropriate occupational safety measures when encountering a suspect who is a PWID.

Module III covers public health-based interventions targeting PWID (SEPs, OST) and deconstructs myths typical among law enforcement (ie, drug users do not care about their health, SEPs increase the risk of NSIs). A video vignette provides an overview of the functioning of an SEP and OST, as well as a testimonial by a former drug user who speaks about his experiences with police on the street and his successful drug rehabilitation.

\section{Fidelity}

ICAP Instructors will be informed that all of their classes will be audio recorded as part of our process evaluation, and that results will not be shared with their supervisors. Study staff attending each class complete a fidelity checklist that documents the extent to which the instructor adequately covered the key elements of each PEP module. Items are assessed on a Likert scale using the stem, "To what extent did the instructor..."? The field coordinator and project director will independently code the same recordings and inter-rater reliability will be assessed. Checklists with agreement $<90 \%$ will trigger a third rater. Checklists will be reviewed by the Data Manager and the investigators will be informed if any checklist totals are $<90 \%$, which would indicate that retraining of instructors may be needed. We describe below the design of the PEP evaluation (Proyecto ESCUDO).

\section{Study design}

ESCUDO is a hybrid type 1 design that simultaneously tests an intervention and an implementation strategy. ${ }^{71}$ This study has three levels: (1) Implementation of the PEP across the entire Tijuana police department using a stepped wedge design, and evaluating department-wide 


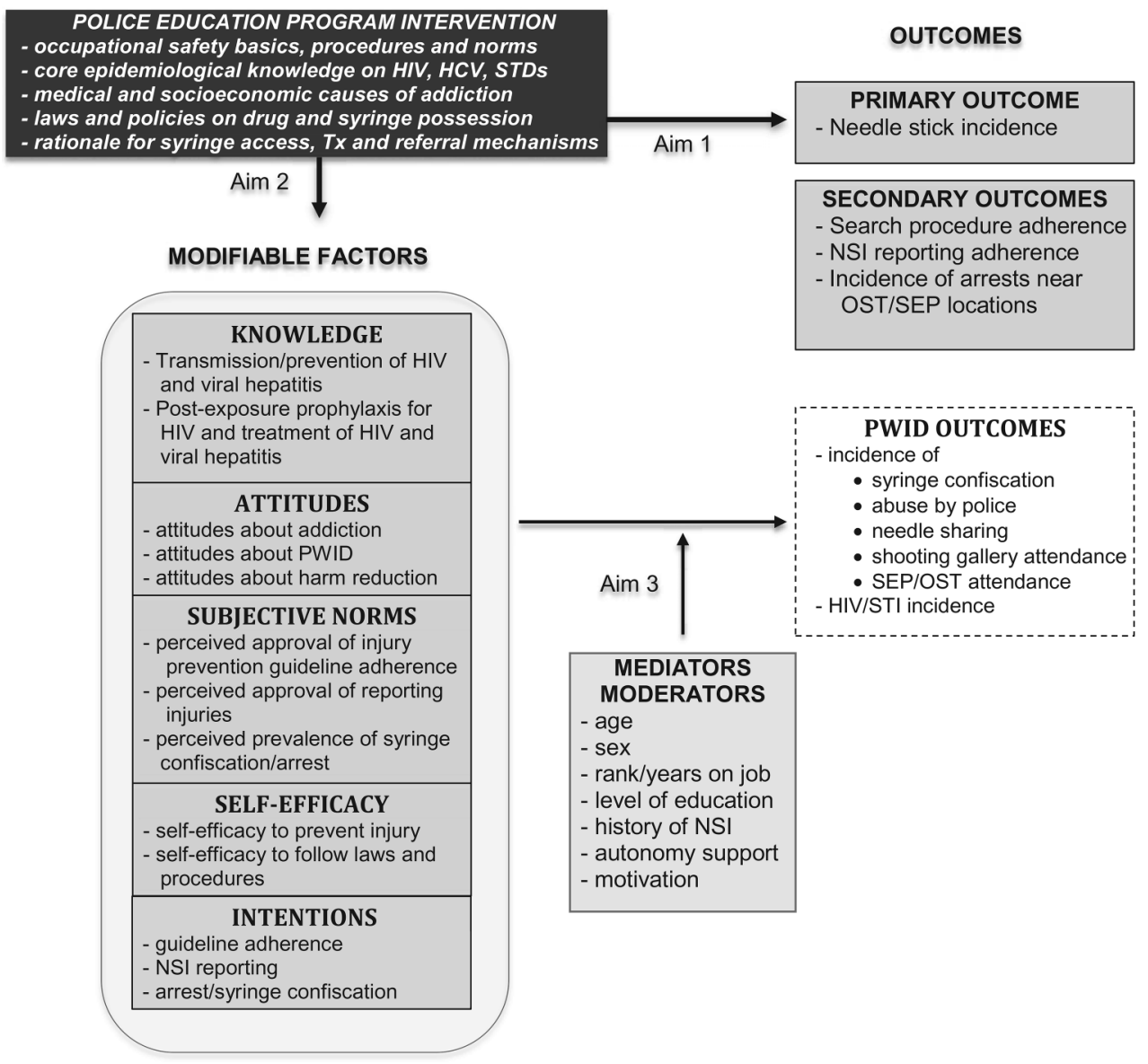

Figure 1 Conceptual model to evaluate the impact of a police education programme.

NSI incidence for the primary study outcome; (2) Prospective 24-month follow-up of a random subcohort of police officers sampled from each PEP class to assess behavioural outcomes; (3) Simultaneous longitudinal follow-up of a parallel cohort of PWID to independently assess their experiences with police. Each of these components is described below.

\section{Level 1: implementation of the PEP across the Tijuana police department}

ESCUDO was initially conceived as a modified steppedwedge randomised controlled trial involving a staggered roll-out of the PEP where participants are randomly selected to transition from the control to intervention in classes of equal numbers over a 2-year period. However, since randomly assigning officers to PEP classes would interfere with the department's programmatic priorities, we modified the design to integrate the PEP into regularly scheduled refresher training classes that were being held for other purposes (eg, basic police tactics). The design we adopted maintains core features of a stepped wedge design, whereby the preintervention period for each officer is treated as the control. On a weekly basis, one cluster (ie, class of 20-50 officers from different ranks and precincts undergoing a regularly scheduled refresher training) will 'step up' and cross over from the control to the intervention condition by receiving PEP training, until the entire force of 1200 street-level officers is trained. As shown in figure 2, the incidence of NSIs (primary outcome, aim 1) and incidence of arrests near SEPs and drug treatment programmes (secondary outcome, aim 2) will be assessed for the entire police department based on de-identified data.

\section{Outcome ascertainment for level 1}

The primary end point of Proyecto ESCUDO is NSI incidence (aim 1). Since NSIs tend to be under-reported, we will collect these data in two ways: (1) Through the NSI Surveillance and Response Programme (NSRP) based on prospective data from the entire police department (Level 1); (2) Through the ESCUDO subcohort $(\mathrm{N}=500$; Level 2; see below). The first approach utilises the NSRP that was implemented in 2014 by our team in collaboration with the Police Department and the Office of Municipal Health (DMS) in Tijuana. The NSRP encourages officers experiencing an NSI to notify their direct supervisor and immediately go to the main office of the DMS Department of Legal Medical Experts. These are staffed $24 \mathrm{~h}$ a day by a certified medical doctor in a private medical examination room where they complete an NSI Exposure Report Form detailing the circumstances of exposure. To facilitate reporting of 
Police Education Program (PEP) delivered to all street-based Tijuana Police Officers in a modified step wedge design
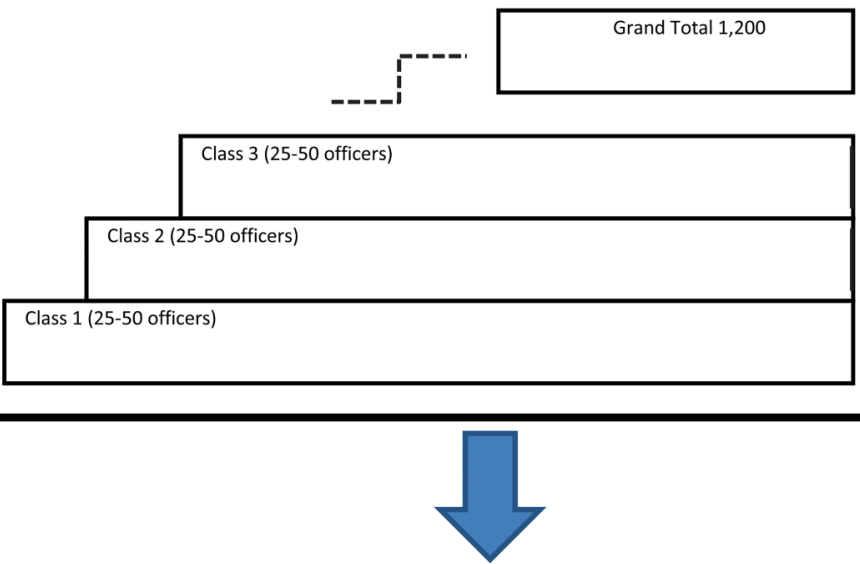

Outcomes assessed prospectively department-wide $(n=1,200)$

Primary outcome (Aim 1): Needle stick incidence (NSI) assessed through NSI Surveillance and Response Program

Secondary outcomes (Aim 2): Knowledge and Attitudes assessed through pre and post PEP surveys

Adverse Behaviors (e.g., arrests of people who inject drugs near SEPs and drug treatment programs)

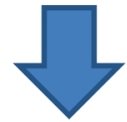

Random Sub-cohort assessed 3, 6, 12, 18 and 24 months post-PEP training $(n=500)$

Primary Outcome (Aim 1): Self-reported NSIs

Secondary outcomes (Aim 2): Knowledge, attitudes, adverse and protective behaviors through follow-up

surveys

Mediators/Moderators (Aim 3): Experience as a police officer, changes in knowledge, attitudes and

behaviors, motivations assessed through follow-up surveys

Figure 2 Study design of Project ESCUDO (SHIELD).

NSIs, the Tijuana police cars have a sticker outlining the NSI protocol, and the State Ministry of Health Office in Tijuana has made free HIV, hepatitis C, syphilis and hepatitis B tests available on site. NSI forms will be kept in a locked cabinet on site; the Head of Planning and Special Projects at Tijuana's Police Department will provide quarterly reports to our team and the Data Safety and Monitoring Board including date of NSI, whether the officer had undergone the PEP, date of training and context of the NSI. No identifiers are included. Cumulative NSI incidence will be measured over a 3-year period to accommodate the implementation of the step-wedge design intervention framework.

\section{Survey data}

Police officers who consent to ESCUDO are given pre-PEP and post-PEP surveys that are self-administered. Each survey takes 10-15 min to complete. The survey assesses lifetimes and recent on-duty NSIs (aim 1), and knowledge, attitudes, subjective norms, intentions, selfefficacy for adopting protective behaviours and adverse and protective behaviours affecting NSIs and acquisition of HIV and other blood-borne infections (aim 2). The survey was adapted from items previously used by Beletsky $e t a l^{869}$ in domestic and international settings, ${ }^{70}$ and piloted in Tijuana. Since knowledge of HIV/AIDS in Tijuana is low, ${ }^{72}$ we will utilise an 18-item true/false scale that assesses the awareness of HIV symptoms, transmission and prevention (eg, "People who have been infected with HIV quickly show serious signs of illness"). ${ }^{73} \mathrm{We}$ have used this scale in other Tijuana studies $(\alpha=0.75$ to 0.89 ; test-retest reliability $=0.76$ to 0.94 ). Attitudinal, subjective (perceived social) norms, self-efficacy and intention items developed by Fisher and Fisher will be assessed using a 5-item Likert scale (strongly agree-strongly disagree). ${ }^{74}$ Items expressing both positive and negative 
statements like "Syringe Exchange Programs increase the risk of needle-stick injuries for police" will assess attitudes on vulnerable groups. For subjective norms, statements like "most of my colleagues think it's important to follow official search safety procedures" will be utilised. Self-efficacy for preventive behaviours will be assessed by items like "I am confident that I can prevent on-duty NSIs." To assess intended practices, we will utilise items such as "Next time a suspect informs me that he has a syringe, I will confiscate it." These domains are consistent with central tenets of TPB. ${ }^{58}$

SDT highlights the importance of motivational regulation and autonomy support in evaluating training interventions. To measure motivational constructs, we adopted items from the Perceived Locus of Causality scale and the corollary amotivation subscale. ${ }^{75}$ Items using the stem, 'I am participating in this training because:' will list four items per scale. Measures include 'trainings are interesting and fun' (intrinsic motivation; $\alpha=0.88$ ), 'because occupational safety is important to me' (identified regulation), 'because I am required to do so' (external regulation; $\alpha=0.81$ ) and 'but I am not interested in this topic' (amotivation; $\alpha=0.84$ ) ${ }^{62}$ Support for these measures is based on diverse training and other intervention evaluation research, including Spanish-speaking settings. ${ }^{62}$ 75-78 Autonomy support from supervisors will be measured using an adaptation of the Health Care Climate Questionnaire, ${ }^{79}$ which uses an analogous Likert framework with a series of items such as: 'My supervisor understands me' $(\alpha=0.92)$. Use of these measures is supported by prior research in injury prevention among police. ${ }^{56}$

Behavioural outcomes include behaviours that adversely affect the risk of blood-borne transmission among officers and PWID (syringe confiscation) and protective behaviours (use of barrier protection during pat-downs and arrests). On leaving the classroom, study staff collect the informed consent forms and surveys and provide each officer with two movie tickets as a means of compensation.

\section{Geocoded arrest data}

In addition to NSI surveillance data, the Tijuana police department is providing our team with geocoded arrest data to determine the extent to which the PEP decreases the number of arrests near SEP and OST sites in Tijuana (aim 2). On the basis of the methodology developed during preliminary studies, ${ }^{80}$ we will examine spatial overlap between drug-related arrests and SEPs/drug treatment sites using data mapped into GIS-based software, ArcMap V.10.1 (ESRI, Redlands, California, USA). Available drug possession arrest data include all arrests in which $\geq 1$ charge concerned drug possession over the legal limit, drug-related crimes, the neighbourhood (colonia) where the arrest occurred and the month of arrest. Using the Getis-Ord Gi* statistic, we will examine spatial patterns to identify hotspots of drug-related arrests at the colonia-level per 1000 adult residents (eg, neighbourhoods with significantly higher or lower rates of arrests than expected if arrests were randomly distributed across space). We will determine whether there was a higher rate of drug-related arrest in colonias with better access to SEPs/OST sites. Access to SEPs/drug treatment sites will be determined by applying a method proposed by Cooper $e t a l^{81}$ that calculates the per cent of a colonia's surface area within a $1350 \mathrm{~m}$ radius of a SEP/drug treatment site (the $1350 \mathrm{~m}$ buffer zone corresponds to the median area of colonias in Tijuana). Colonias with no surface area within the buffer zone will be defined as not having access. Further, we examine whether there is a significant increase in the average number of arrests in colonias with greater surface area within the buffer zone through modelling this relationship using Poisson regression.

\section{Level 2: prospective follow-up of a random subcohort of police officers}

Assessing NSI incidence solely through a passive reporting system would be inadequate since previous studies suggest considerable under-reporting. ${ }^{46}{ }^{82}$ Furthermore, aim 2 of Proyecto ESCUDO is to determine whether the PEP changes policing behaviours. Therefore, we will assess self-reported NSIs, changes in attitudes about HIV and related infections, attitudes towards PWID and adverse and protective behaviours that influence bloodborne transmission risks among police and PWID as secondary outcomes among a subcohort of police officers sampled from PEP classes. Specifically, at the beginning of each PEP session, staff will explain to the class of police officers that while the PEP training is mandatory, the ESCUDO evaluation is voluntary. Officers not wishing to participate are told that they can submit blank pre-PEP and post-PEP surveys if they do not wish to disclose their non-participation. A unique identification code will be generated for each officer, based on their day of birth, first initial, first letter of father's last name and mother's last name. Written informed consent to participate in ESCUDO is then obtained for the pre-PEP and post-PEP surveys, as well as a separate consent for follow-up. Only the latter consent asks for personal information to permit study staff to contact them. The consent form for follow-up also asks each officer whether they had ever encountered syringes on duty and in the past 6 months.

Eligibility criteria for the level 2 component of the study require that only officers who consent to complete the pre-PEP and post-PEP surveys and report encountering syringes within the past 6 months comprise the follow-up sampling frame. To achieve sufficient power, the study statistician applies an algorithm to randomly sample approximately $42 \%$ of the eligible officers from each class of 20-50 officers who are subsequently contacted for follow-up visits. A total of 500 officers in the subcohort will be recruited. This subcohort will undergo self-administered surveys pre-PEP, 
immediately post-PEP and 3, 6, 12, 18 and 24 months post-PEP.

While this design has standard features of a stepped wedge design (ie, staggered transition from control to intervention), the evaluation differs. Unlike the standard stepped wedge design where every cluster is assessed at each step, only one cluster will be evaluated per step for most secondary outcomes. This was performed because it would be impractical to follow 1200 officers for 2 years, and power is sufficient with a sample size of 500 for most outcomes (see Analysis). Unlike the traditional step wedge design where evaluation stops once the last cluster transitions from control to intervention, each member of the subcohort will be followed for 2 years.

\section{Follow-up survey}

While all 1200 police officers are invited to complete the pre-PEP survey and post-PEP survey immediately following the training with informed consent, the post-PEP follow-up interviews occurring at 3, 6, 12, 18 and 24 months post-training are to be conducted exclusively on the subcohort $(\mathrm{N}=500)$. The above measures will be adapted to focus on the appropriate recall period. Participants will receive a voucher for movie tickets (equivalent US\$20) for each follow-up interview.

\section{Follow-up}

Annual attrition in the Tijuana police department is $6.2 \%$, but we have conservatively powered our analysis for $10 \%$ attrition per year. Follow-up interviews will be conducted only among the subcohort $(\mathrm{N}=500)$, who will be asked to provide locator information at their baseline interview (ie, home and cell phone, pager, email, address) and ways they prefer to be contacted (eg, SMS text).

\section{Statistical analysis (aims 1-3)}

The primary analysis will consist of examining outcomes in the pre-PEP versus post-PEP period utilising generalised linear mixed models (GLMM) applied to repeated measures analysis of clustered data. Mixed effects models will allow us to adjust for both within-subject and within-cluster correlations; one random effect will capture the within-cluster correlation and another will capture the nested subject-within-cluster correlation. These random effects will be used in all analyses described below.

\section{Aim 1}

NSI incidence estimates (pre-PEP and post-PEP) along with 95\% CIs will be calculated based on data from the department-wide NSI surveillance system (level 1) and our subcohort (level 2).

In $\mathrm{H} 1$, we will test the hypothesis that departmentwide, the PEP will be associated with a significant decline in NSI incidence over 2 years of follow-up as the PEP intervention is scaled up. To evaluate $\mathrm{H} 1$, we will fit a Poisson random effects model, with the number of incident NSIs reported by each police officer, under the surveillance system, as the outcome variable, log (length of time spent under each condition pre-PEP and post-PEP) as an offset variable to account for the time spent at risk for an NSI, while controlling for possible confounders (eg, district, gender, rank). The intervention indicator variable (pre-PEP vs post-PEP) will be used as the main fixed effect. Furthermore, cluster will be used as a random effect to control for intracluster correlation and subject will also be used as a random effect to control for the correlation of multiple events for the same individual. Also, temporal variations will be evaluated and controlled for as follows. A calendar time variable indicating the time of training will be created and the interaction between this variable and the intervention will be assessed to determine if any significant temporal changes took place. Since we expect that each class will perform better after receiving the training as opposed to before receiving the training, regardless of time when the training is conducted, no confounding interaction between time of training and intervention is expected. However, it is possible that the magnitude of the effect might depend on time (eg, significant interaction but not confounding). If such an interaction is found, the main effect of intervention can be interpreted from the full model (factoring in the interaction). If by any chance the interaction is found to be confounding (ie, officers trained during a certain time period did worse post-training as opposed to pretraining), we will estimate the effect of the intervention separately by calendar time of entry.

\section{Aim 2}

To test H2.1 and H2.2, that the PEP is associated with improvements in: knowledge of transmission, prevention and treatment of HIV and related infections (H2.1), attitudes towards PWID, sex workers and HIV-infected persons (H2.2), we will fit linear mixed models, with HIV knowledge score (H2.1) and attitudes score (H2.2), respectively, as outcome variables and Time (pre-PEP training, post-PEP training, 3, 6, 12, 18 and 24 months post-PEP training) and as the main fixed effect. Contrasts between pre-PEP and other time periods will be evaluated to determine the short-term and long-term PEP effects.

To test H2.3, (PEP is associated with fewer reports of syringe confiscation), we will fit a Generalised Poisson Regression Mixed Model, with the rate of syringe confiscation by police as an outcome variable. To evaluate H2.4, which is to compare the rate of arrests that occur near SEP and drug treatment programmes (pre-PEP and post-PEP), we will fit Poisson Regression Mixed Models, with the number of arrests (per police officer per month) near these locations as outcome variables, $\log$ (total number of arrests) as an offset term and the intervention indicator variable (pre-PEP vs post-PEP) as the main fixed effect. To test H2.5, which is that the PEP 
will be associated with significant increases in the use of barrier protection during pat-downs and arrests, we will fit a Poisson Regression Mixed Model with random effect, with the rate of using gloves (per police officer per PWID stopped by police) as an outcome variable.

\section{Aim 3}

To assess H3.1, which tests if SDT constructs (eg, motivation, years spent in the police force and autonomous support from supervisors) moderate the PEP effects, we will include an interaction term between the main fixed effect (Intervention=Pre-PEP, Post-PEP) and the moderator in question (eg, autonomous support from supervisors), within each model used to assess the effect of the intervention on various outcomes. If an interaction term is significant, further stratified analyses will be conducted to determine the effect of the PEP at each level of the moderator in question (eg, PEP effect among those who have autonomous support from supervisors vs those who do not, respectively).

Stepped wedge designs reduce contamination bias, considering that each cluster (here, each class) acts as its own control and hence provides data in the control and intervention periods. ${ }^{83}$ Some degree of contamination is likely since PEP classes will occur over 2 years and because of the social nature of policing. We will attempt to measure this by asking officers in the subcohort whether other officers had discussed any of the training topics with them prior to receiving the PEP, and whether they discussed any of the training topics with other officers post-PEP. These circumstances will be considered as variables in our outcome analyses. Although we expect change to occur in a linear manner (eg, as more officers are trained, fewer NSIs occur), the intervention effect could be curvilinear due to diffusion of information from trained to untrained officers. As such, we will test for both linear and non-linear effects of time on the outcome.

\section{Power calculations}

Using PASS software, all power calculations except H1 were based on two-sided tests, with a 0.05 type I error rate, $\mathrm{N}=500$, a conservative $10 \%$ annual attrition (ie, $\mathrm{N}=405$ ), and a design effect of 1.4. The latter controls for within-cluster correlation and was derived using the formula (1+ (cluster size-1) xintracluster correlation) ( $r$ ), where average cluster size $=16$ and $r$ is assumed to be 0.03. After adjusting for attrition and clustering, the effective $\mathrm{N}$ is 289. Power for $\mathrm{H} 1$ was based on a nominal $\mathrm{N}$ of 1200 and on an effective $\mathrm{N}$ of 689 (after accounting for a design effect of 1.74 , given an average class size of 35 and $\mathrm{r}=0.02$ ). Since our study population consists of the 2000 Tijuana police officers, for all the power calculations, a finite population correction was used, reducing the SE of the mean by a given factor (SQRT $((\mathrm{N}-\mathrm{n})$ / $\mathrm{N}-1)$ ), where $\mathrm{N}$ represents the population size and $\mathrm{n}$ the sample size.
To test the hypothesis that the PEP is associated with a significant decline in NSI incidence (H1), calculations were based on a 1-sample Wilcoxon test of the difference between pre-PEP and post-PEP incidence, with the NSI incidence assumed to follow a Poisson distribution. Table 1 shows that if the pre-PEP NSI incidence per officer is $0.05,0.06,0.07$ or 0.08 , respectively, with an effective $\mathrm{N}$ of 689 , we have $>80 \%$ power to detect a difference in NSI incidence between the pre-PEP and post-PEP of 0.0075 (post-PEP rate=0.0425), 0.0075 (post-PEP rate $=0.0525), 0.0074$ (post-PEP rate $=0.0626$ ) and 0.0076 (post-PEP rate $=0.0724$ ), respectively. According to our pilot survey, we would expect an average of 0.06 incident NSI cases/police officer to occur during the pre-PEP period. Using this estimate, the smallest decline in NSI incidence we can detect with $80 \%$ power is $12.5 \%$.

To test the effect of the PEP on knowledge of transmission, prevention and treatment of HIV and viral hepatitis (H2.1), we used a 1-sample paired t test. If we assume that the pre-PEP mean knowledge scores are 2.6, 2.8 or 3.0 , respectively, with an effective $\mathrm{N}$ of 298 , we have $>80 \%$ power to detect a difference between pre-PEP and post-PEP scores if the latter is 2.65, 2.85 and 3.05, respectively. The smallest difference that we can detect between the prescore and postscore is 0.05 (SD: 0.32). According to our pilot, the pre-PEP score and SD were $2.79(0.27)$ and the post-PEP score was 3.15 (0.37), which is a difference of 0.36 . Therefore, we are powered to detect a much smaller difference.

To test the PEP effect on syringe confiscation (H2.3), we used a 1-sample paired test with syringe confiscation rates following a Poisson distribution. If we assume that pre-PEP, an officer confiscates syringes at an average rate of $0.65,0.80,0.95$ syringes/PWID/week (corresponding to 5,6 or 7 syringes/week), with an effective $\mathrm{N}$ of 298 , we have $>80 \%$ power to detect a difference between pre-PEP vs post-PEP if the latter is $0.51,0.66$ and 0.81 , respectively, corresponding to 4,5 or 6 syringes/week. The smallest change we can detect is of 1 syringe/ PWID/week.

To test the effect of the PEP on the number of arrests near SEP and drug treatment programmes (H2.4), calculations were based on a one-sample paired test with the number of arrests assumed to follow a Poisson distribution. On the basis of the 2013 arrest data from the Tijuana police department, these averaged 2593 arrests/ month. According to our parallel cohort of PWID in Tijuana, 25.4\% of PWID reported arrests within 500 metres of a drug treatment centre. Since this may overestimate the actual arrest rate, we used it as an upper limit in power calculations, assuming an actual rate of $10-25 \%$. With a police force of 2000 , we assumed that a pre-PEP arrest rate (per month/per officer) is 1.3. Given these assumptions, if the pre-PEP arrest rates near drug treatment programmes are 0.13 (ie, $10 \%$ of total arrests), 0.19 (15\% of total arrests), 0.26 (20\% of total arrests) or 0.32 (25\% of all arrests), with an 
Table 1 Effect sizes detectable with $80 \%$ power for aim 1, hypothesis 1 of Proyecto ESCUDO

\begin{tabular}{lllll}
\hline $\begin{array}{l}\text { Pre-PEP NSI } \\
\text { incidence }\end{array}$ & $\begin{array}{l}\text { Post-PEP NSI } \\
\text { incidence }\end{array}$ & $\begin{array}{l}\text { Difference in } \\
\text { pre-post PEP NSI } \\
\text { incidence }\end{array}$ & $\begin{array}{l}\text { SD of the } \\
\text { difference }\end{array}$ & $\begin{array}{l}\text { Per cent } \\
\text { decline in } \\
\text { NSI incidence (\%) }\end{array}$ \\
\hline 0.05 & 0.0425 & 0.0075 & 0.0866 & 15 \\
0.06 & 0.0525 & 0.0075 & 0.0866 & 12.5 \\
0.07 & 0.0626 & 0.0074 & 0.0860 & 10.5 \\
0.08 & 0.0724 & 0.0076 & 0.0872 & 9.5 \\
\hline NSI, needle stick incidence; PEP, police education programme.
\end{tabular}

effective $\mathrm{N}$ of 689 officers, we have $>80 \%$ power to detect a difference in the arrest rate between the pre-PEP and post-PEP, if the latter is $0.12,0.17,0.24$ or 0.29 , respectively (ie, decline in the arrest rate of $\sim 9 \%$ ).

\section{Level 3: prospective follow-up of a parallel cohort of PWID}

Although we aim to shift police attitudinal norms about PWID, sex workers and HIV-positive persons and reduce adverse behaviours through a theory-driven framework (aim 2), it is unrealistic to expect police to admit misconduct (eg, physical or sexual abuse, soliciting bribes) to interviewers. Fortunately, we are in the unique position of having a parallel cohort of PWID in Tijuana. ${ }^{84}$ Since 2010, 866 PWIDs have undergone semiannual HIV tests and surveys including questions on police encounters. This includes negative experiences such as syringe confiscation, arrests near SEPs and drug treatment sites, sexual and physical abuse by police, as well as positive experiences, such as police referrals to SEPs or OST. The availability of these data enables us to externally assess the impact of the PEP on PWID risk behaviours by comparing PWIDs' policing experiences before versus after PEP. Since $\mathrm{El}$ Cuete is funded through 2020, we will have data pre-PEP, during the 2 years of PEP scale-up, and 2 years post-PEP. To evaluate the PEP's effect on these outcomes, we will use GLMM with random intercepts and slopes. Poisson models will be used for count outcomes (eg, \# of syringes confiscated by police) and logistic models for binary outcomes (eg, sexual or physical abuse by police). Variables will be created to indicate the PEP phase (pre-PEP, during-PEP, post-PEP) and time within each PEP phase (start-phase, 6 months, 12 months, 18 months, end-phase) along with their interaction (PEP phasexTime) in regression models. We hypothesise a significant interaction between the PEP phase and Time, with the sharpest declines being observed during the post-PEP phase. We will also create models with interview time (baseline, 6 months, 12 months, through 72 months) as the sole main fixed effect and introduce a quadratic term, as we may observe a curvilinear trend due to the PEP over time. These findings and results from Proyecto ESCUDO will be used to inform cost-effectiveness analyses, using measures collected from both police and PWID in sensitivity analyses.

\section{ETHICS/DISSEMINATION}

Research ethics approval for Proyecto ESCUDO was obtained from the Human Research Protections Programme of the University of California San Diego and Xochicalco University.

Proyecto ESCUDO is the first trial to assess the efficacy of a PEP on policing behaviours that places both PWID and police at an elevated risk of HIV and other bloodborne infections. Since Proyecto ESCUDO is powered to assess efficacy based on an objective outcome (NSI incidence), results are expected to influence the PEP uptake in the growing number of countries where policing is a key driver of HIV acquisition. For example, a modelling scenario found that if police beatings were eliminated in Odessa, Ukraine, HIV incidence among PWID could decrease up to $19 \% .^{85}$

As more countries relax drug policies, police altercations with PWID and NSI risks will most likely increase in the absence of appropriate police training like we propose. If PEPs are efficacious, they could avert not just HIV but other infections that are entrenched in marginalised populations (eg, viral hepatitis), as well as improve the uptake of SEPs and substance use treatment modalities. $^{86}$ Our study is responsive to the Global Commission on HIV and Drugs, Global Commission on Drug Policy ${ }^{30}$ and other calls to action for HIV structural interventions. ${ }^{87-92}$

Tijuana is an ideal location to test PEP efficacy, as policing practices are a major driver of HIV infection among PWID in many countries. ${ }^{5} 6328093-96$ Mexico is set to scale up SEP and OST, but their success is undermined by police resistance, corruption and police harassment of PWID, as is the case elsewhere. ${ }^{12}$ Our intervention is timely as the Tijuana Police Department has committed to institutionalising the PEP, and later extending it to cadets, pending our outcome data. Mexican policymakers have pledged that future health and drug policy decisions will be based on evidence and human rights, signalling a new era and opportunities for novel interventions and cross-sectoral collaborations that better align policing with public health. ${ }^{97}$

Proyecto ESCUDO is innovative in its programmatic focus and methodology. First, it is one of the few interventions attempting to alter the law enforcement environment for infectious disease transmission, and is responsive to the recent call for 'political 
epidemiology'. ${ }^{98}$ Second, although we expect that the PEP will have a direct impact on police officer safety, another extremely important benefit will be its indirect public health impact on PWID who regularly report on their encounters with police that have a significant impact on HIV risk behaviour (studied through our separately funded cohort, Proyecto El Cuete). Third, our use of a modified stepped wedge design is novel and ideally suited for cases like ours when an intervention is presumed to do more good than harm, it is logistically impractical to offer the intervention simultaneously to all participants, and study outcomes do not require an overly long follow-up. ${ }^{83}$ Fourth, our use of geocoded arrest data obtained through our collaboration with the Tijuana police will allow us to objectively determine the extent to which the PEP is associated with changing arrest patterns (eg, intensity of arrests occurring near SEP and OST). If our study findings are positive, we will enlist assistance from the Law Enforcement and HIV Network (http://www.leahn.org) to widely disseminate our PEP materials as a potential model for other countries.

\section{Author affiliations \\ ${ }^{1}$ Department of Medicine, University of California San Diego, La Jolla, California, USA \\ ${ }^{2}$ Xochicalco University, Tijuana, Baja California, Mexico \\ ${ }^{3}$ U.S.-Mexico Border Health Commission, Mexico Section, Tijuana, Baja California, Mexico \\ ${ }^{4}$ Secretary of Municipal Public Safety, Tijuana, Baja California, México ${ }^{5}$ School of Law and Bouvé College of Health Sciences, Northeastern University, Boston, Massachusetts, USA}

Acknowledgements The authors gratefully acknowledge support from the Tijuana Mayor's Office, Police Department, Police Academy and Secretaries of Public Safety and Health. Special thanks to Comandante Salvador Mendoza Madrid, Arnulfo Bañuelos Pérez, Víctor Manuel Alaníz Morales, Jim Hughes and Antonio Granillo. Support for the development and piloting of the PEP was provided through grants from the Open Society Foundations Latin America Program grant OR2013-11352 and UCSD Center for AIDS Research International Pilot Grant NIAID 5P30AI036214. Support for NSRP and video vignettes development was provided by the Fogarty International Center of the National Institutes of Health, Award Number D43TW008633 (AITRP: Rolón, Patiño, Arredondo, Rocha and Strathdee). Projects ESCUDO and El Cuete are supported by the National Institute on Drug Abuse (R01DA039073 and R37DA019829).

Contributors SAS and LB conceived of the study. SAS, LB and TP designed the evaluation. SAS, DA, TLP and TG developed the statistical analysis. LB designed the PEP; LB and TLP conceived the conceptual framework. LB, JA, TR, HOO and MEP refined and culturally adapted the PEP content. LB, JA, TR and MLR designed the pre-PEP and post-PEP surveys. SAS, TLP and LB wrote the protocol. All authors read and assisted in editing the manuscript.

Funding National Institute on Allergy and Infectious Diseases (5P30Al036214). National Institute on Drug Abuse (R01DA039073, R37DA019829). Fogarty International Center (D43TW008633). Open Society Foundations.

\section{Competing interests None declared.}

Patient consent Obtained.

Ethics approval UCSD HRPP and Xochicalco University.

Provenance and peer review Not commissioned; peer reviewed for ethical and funding approval prior to submission.
Open Access This is an Open Access article distributed in accordance with the Creative Commons Attribution Non Commercial (CC BY-NC 4.0) license, which permits others to distribute, remix, adapt, build upon this work noncommercially, and license their derivative works on different terms, provided the original work is properly cited and the use is non-commercial. See: http:// creativecommons.org/licenses/by-nc/4.0/

\section{REFERENCES}

1. Strathdee SA, Stockman JK. Epidemiology of HIV among injecting and non-injecting drug users: current trends and implications for interventions. Curr HIV/AIDS Rep 2010;7:99-106.

2. Nelson P, Mathers B, Cowie B, et al. Global epidemiology of hepatitis $B$ and hepatitis $C$ in people who inject drugs: results of systematic reviews. Lancet 2011;378:571-83.

3. Bluthenthal RN, Lorvick J, Kral AH, et al. Collateral damage in the war on drugs: HIV risk behaviors among injection drug users. Int $J$ Drug Policy 1999;10:25-38.

4. Shannon K, Rusch M, Shoveller J, et al. Mapping violence and policing as an environmental-structural barrier to health service and syringe availability among substance-using women in street-level sex work. Int J Drug Policy 2008;19:140-7.

5. Pollini RA, Brouwer KC, Lozada RM, et al. Syringe possession arrests are associated with receptive syringe sharing in two Mexico-US border cities. Addiction 2008;103:101-8.

6. Strathdee SA, Lozada R, Martinez G, et al. Social and structural factors associated with HIV infection among female sex workers who inject drugs in the Mexico-US border region. PLOS ONE 2011;6: e19048.

7. Beletsky L, Lozada R, Gaines T, et al. Syringe confiscation as an HIV risk factor: the public health implications of arbitrary policing in Tijuana and Ciudad Juarez, Mexico. J Urban Health 2013:90:284-98.

8. Hammett T, Bartlett N, Chen Y. Law enforcement influences on HIV prevention for injection drug users: observations from a cross-border project in China and Vietnam. J Urban Health 2005;82:34-42.

9. Small W, Kerr T, Charette J, et al. Impacts of intensified police activity on injection drug users: evidence from an ethnographic investigation. Int J Drug Policy 2006;17:85-95.

10. Strathdee SA, Fraga WD, Case P, et al. "Vivo para consumirla y la consumo para vivir" ["I live to inject and inject to live"]: high-risk injection behaviors in Tijuana, Mexico. J Urban Health 2005;82(3 Suppl 4):iv58-73.

11. Rhodes $T$, Mikhailova L, Sarang A, et al. Situational factors associated with drug injecting, risk reduction, and syringe exchange practices in Togliatti City, Russian Federation. Soc Sci Med 2003;57:39-54.

12. Cooper HL, Des Jarlais DC, Tempalski B, et al. Drug-related arrest rates and spatial access to syringe exchange programs in New York City health districts: combined effects on the risk of injection-related infections among injectors. Health Place 2012;18:218-28.

13. Aitken $C$, Moore D, Higgs $P$, et al. The impact of a police crackdown on a street drug scene: evidence from the street. Int $J$ Drug Policy 2002;13:189-98.

14. Blankenship KM, Koester S. Criminal law, policing policy, and HIV risk in female street sex workers and injection drug users. $J$ Law Med Ethics 2002;30:548-59.

15. Cooper H, Moore L, Gruskin S, et al. Characterizing perceived police violence: implications for public health. Am J Public Health 2004:94:1109-18.

16. Cooper H, Moore L, Gruskin S, et al. The impact of a police drug crackdown on drug injectors' ability to practice harm reduction: a qualitative study. Soc Sci Med 2005;61:673-84.

17. Davis CS, Burris S, Kraut-Becher J, et al. Effects of an intensive street-level police intervention on syringe exchange program use in Philadelphia, PA. Am J Public Health 2005;95:233-6.

18. Friedman SR, Cooper HL, Tempalski B, et al. Relationships of deterrence and law enforcement to drug-related harms among drug injectors in US metropolitan areas. AIDS 2006;20:93-9.

19. Kerr T, Small W, Wood E. The public health and social impacts of drug market enforcement: a review of the evidence. Int J Drug Policy 2005;16:210-20.

20. Koester S, Booth R, Zhang Y. The prevalence of additional injection-related HIV risk behaviors among injection drug users. $J$ Acquir Immune Defic Syndr Hum Retrovirol 1996;12:202-7.

21. Beletsky L, Heller D, Jenness S, et al. Syringe access, syringe sharing, and police encounters among people who inject drugs in New York City: a community-level perspective. Int J Drug Policy 2014;25:105-11. 
22. Hayashi K, Kerr T. Police interference with methadone treatment in Bangkok, Thailand. Int J Drug Policy 2015;26:112-15.

23. Wood E, Spittal PM, Small W, et al. Displacement of Canada's largest public illicit drug market in response to a police crackdown. CMAJ 2004;170:1551-6.

24. Werb D, Wood E, Small W, et al. Effects of police confiscation of illicit drugs and syringes among injection drug users in Vancouver. Int J Drug Policy 2008;19:332-8.

25. Booth RE, Dvoryak S, Sung-Joon M, et al. Law Enforcement practices associated with HIV infection among injection drug users in Odessa, Ukraine. AIDS Behav 2013;17:2604-14.

26. Ti L, Hayashi K, Kaplan K, et al. HIV test avoidance among people who inject drugs in Thailand. AIDS Behav 2013;17:2474-8.

27. Burris S, Blankenship KM, Donoghoe M, et al. "Risk Environment" for injection drug users: the mysterious case of the missing cop. Milbank Q 2004;82:125-56.

28. Robertson AM, Vera AY, Gallardo M, et al. Correlates of seeking injection assistance among injection drug users in Tijuana, Mexico. Am J Addict 2010;19:357-63.

29. Meeting of the International Task Force for Disease Eradication, April 2011. Releve epidemiologique hebdomadaire/Section d'hygiene du Secretariat de la Societe des Nations=Weekly epidemiological record/Health Section of the Secretariat of the League of Nations. 2011;86:341-51.

30. Global Commission on Drugs. The war on drugs and HIV/AIDS: how the criminalization of drug use fuels the global pandemic. Global Comission Drug Policy 2012. http://globalcommissionondrugs.org/ wp-content/themes/gcdp_v1/pdf/GCDP_HIV-AIDS_2012 REFERENCE.pdf (last accessed 13 May 2015).

31. Philbin M, Pollini RA, Ramos R, et al. Shooting gallery attendance among IDUs in Tijuana and Ciudad Juarez, Mexico: correlates, prevention opportunities, and the role of the environment. AIDS Behav 2008;12:552-60.

32. Volkmann $\mathrm{T}$, Lozada $\mathrm{R}$, Anderson $\mathrm{CM}$, et al. Factors associated with drug-related harms related to policing in Tijuana, Mexico. Harm Reduct J 2011;8:7.

33. Werb D, Wagner K, Beletsky L, et al. Police bribery and access to methadone maintenance therapy within the context of drug policy reform in Tijuana, Mexico. Drug Alcohol Depend 2015;148:221-5.

34. Beletsky L, Cochrane J, Smelyanskaya M, et al. Police encounters among needle exchange clients in Baltimore: operationalizing surveillance for structural determinants of health. Am J Public Health 2015;16:e1-e8.

35. Beletsky L, Wagner K, Arredondo J, et al. Implementing Mexico's "Narcomenudeo" drug law reform: a mixed-methods assessment of early experiences among people who inject drugs. JMMR 2015. In press. doi: 10.1177/1558689815575862

36. Banta-Green CJ, Beletsky L, Schoeppe JA, et al. Police officers' and paramedics' experiences with overdose and their knowledge and opinions of Washington State's drug overdose-naloxone-good samaritan law. J Urban Health 2013;90:1102-11.

37. Beletsky L, Thomas R, Smelyanskaya M, et al. Policy reform to shift the health and human rights environment for vulnerable groups: the case of Kyrgyzstan's instruction 417. Health Hum Rights 2012:14:34-48.

38. Beletsky L, Agrawal A, Moreau B, et al. Police training to align law enforcement and HIV prevention: preliminary evidence from the field. Am J Public Health 2011;101:2012-15.

39. Silverman B, Davis CS, Graff-Zivin JS, et al. Harmonizing disease prevention and police practice in the implementation of HIV prevention programs: up-stream strategies from Wilmington, Delaware. Harm Reduct J 2012;16:1-15.

40. Ross RS, Viazov S, Roggendorf M. Risk of hepatitis C transmission from infected medical staff to patients: model-based calculations for surgical settings. Arch Intern Med 2000;160:2313-16.

41. Rafful-Loera C, Zule WA, Gonzalez-Zuniga P, et al. High dead-space syringe use among people who inject drugs in Tijuana, Mexico. Drug Alcohol Depend 2015;146:e75.

42. Bobashev G, Zule WA. Modeling the effect of high dead-space syringes on the human immunodeficiency virus (HIV) epidemic among injecting drug users. Addiction 2010;105:1439-47.

43. Zule WA, Cross HE, Stover J, et al. Are major reductions in new HIV infections possible with people who inject drugs? The case for low dead-space syringes in highly affected countries. Int J Drug Policy 2013;24:1-7.

44. Abdala N, Stephens C, Griffith B, et al. Survival of HIV-1 in syringes. JAIDS 1999;20:73-80.

45. Beletsky L, Macalino G, Burris S. Attitudes of police officers towards syringe access, occupational needle-sticks, and drug use: a qualitative study of one city police department in the United States Int J Drug Policy 2005;16:267-74.

46. Lorentz J, Hill L, Samimi B. Occupational needlestick injuries in a metropolitan police force. Am J Prev Med 2000;18:146-50.

47. Dunleavy K, Taylor A, Gow J, et al. Police officer anxiety after occupational blood and body fluid exposure. Occup Med 2012;62:382-4.

48. Rolon ML, Patiño M, Beletsky L, et al. Más miedo a una enfermedad que a un balazo [More afraid of a disease than a bullet]: implementation of system-wide needlestick injury surveillance system in the Tijuana police department, Mexico Consortium of Universities on Global Health; 26 March 2015. Boston, MA: Annals of Global Health, 2015:81:9.

49. Sonder GJ, Bovee LP, Coutinho R, et al. Occupational exposure to bloodborne viruses in the Amsterdam police force, 2000-2003. Am J Prev Med 2005;28:169-74.

50. Davis CS, Johnston J, de Saxe Zerden L, et al. Attitudes of North Carolina law enforcement officers toward syringe decriminalization. Drug Alcohol Depend 2014;144:265-9.

51. Merchant RC, Nettleton JE, Mayer K, et al. HIV post-exposure prophylaxis among police and corrections officers. Occup Med (Lond) 2008;58:502-5.

52. Pagane J, Chanmugam A, Kirsch T, et al. New York City police officers incidence of transcutaneous exposures. Occup Med (Lond) 1996:46:285-8.

53. Mendoza A, Davis R, Perdomo C, et al. Indicadores de Seguridad Publica en Mexico: una Discusion Conceptual Metodological indicators of public health in Mexico: a conceptual methological discussion. Comision Nacional de Seguridad, 2010.

54. de Garay MES, Shirk D, Ferreira OR. Justiciabarómetro: diagnóstico Integral de la Policía Municipal de Tijuana. Justice in Mexico Project, 2015.

55. Auditoria SdIFA. Secretariado Ejecutivo del SNSP. Auditoría al SNSP, 2007. http://www.asf.gob.mx/Trans/Informes/ir2007i/indice. $\mathrm{htm}$ (last accessed 13 May 2015).

56. Chung-Chan D, Hagger M. Autonomous forms of motivation underpinning injury prevention and rehabilitation among police officers: an application of the trans-contextual model. Motiv Emotion 2012;36:349-64.

57. Deci EL, Ryan RM. Human needs and the self-determination of behavior. Psychol Inquiry 2000;11:227-68.

58. Ajzen I. The theory of planned behavior organizational behavior and human decision processes Science Direct 1991;50:179-211.

59. Sheeran P, Silverman M. Evaluation of three interventions to promote workplace health and safety: evidence for the utility of implementation intentions. Soc Sci Med 2003;56:2153-63.

60. Lajunen T, Rasanen M. Can social psychological models be used to promote bicycle helmet use among teenagers? A comparison of the health belief model, theory of planned behavior and the locus of control. J Safety Res 2004;35:115-23.

61. Chan K, Lonsdale C, Ho PY, et al. Patient motivation and adherence to post-surgery rehabilitation exercise recommendations: the influence of physiotherapists' autonomy supportive behaviors. Arch Phys Med Rehabil 1977;90:1977-82.

62. Standage M, Duda JL, Ntoumanis N. A test of self-determination theory in school physical education. Br J Educ Psychol 2005;75(Pt 3):411-33.

63. Hagger MS, Chatzisarantis NLD. Transferring motivation from educational to extramural contexts: a review of the trans-contextual model. Eur J Psychol Educ 2012;27:195-212.

64. Chan DK, Hagger MS. Self-determined forms of motivation predict sport injury prevention and rehabilitation intentions. J Sci Med Sport 2012;15:398-406.

65. Hagger M, Chatzisarantis NL, Hein V, et al. Teacher, peer and parent autonomy support in physical education and leisure-time physical activity: a trans-contextual model of motivation in four nations. Psychol Health 2009;24:689-711.

66. Hagger MS, Chatzisarantis NL, Culverhouse T, et al. The processes by which perceived autonomy support in physical education promotes leisure-time physical activity intentions and behavior: a trans-contextual model. J Educ Psychol 2003;95:784-95.

67. Pihu M, Hein V, Koka A, et al. How students' perceptions of teachers' autonomy-supportive behaviours affect physical activity behaviour: an application of the trans-contextual model. Eur J Sport Sci 2008;8:193-204.

68. Hagger MS, Chatzisarantis NL, Barkoukis V, et al. Perceived autonomy support in physical education and leisure-time physical activity: a crosscultural evaluation of the trans-contextual model. J Educ Psychol 2005;97:376-90. 
69. Beletsky L, Thomas R, Shumskaya N, et al. Police education as a component of national HIV response: lessons from Kyrgyzstan. Drug Alcohol Depend 2013;132(Suppl 1):S48-52.

70. Davis CS, Beletsky L. Bundling occupational safety with harm reduction information as a feasible method for improving police receptiveness to syringe access programs: evidence from three US cities. Harm Reduct J 2009;14:16.

71. Curran G, Bauer M, Mittman B, et al. Effectiveness-implementation hybrid designs: combining elements of clinical effectiveness and implementation research to enhance public health impact. Med Care 2012;50:217.

72. Robertson A, Ojeda V, Nguyen L, et al. Reducing harm from HIV/ AIDS misconceptions among female sex workers in Tijuana and Ciudad Juarez, Mexico: a cross sectional analysis. Harm Reduct $J$ 2012;9:35.

73. Carey MP, Schroder KE. Development and psychometric evaluation of the brief HIV Knowledge Questionnaire. AIDS Educ Prev 2002:14:172-82.

74. Fisher JD, Fisher WA, Williams SS, et al. Empirical tests of an information-motivation-behavioral skills model of AIDS preventive behavior. Health Psychol 1994;13:238-50.

75. Goudas M, Biddle S, Fox K. Perceived locus of causality, goal orientations, and perceived competence in school physical education classes. Br J Educ Psychol 1994;64:453-63.

76. Otis N, Pelletier LG. A motivational model of daily hassles, physical symptoms, and future work intentions among police officers. J Appl Soc Psychol 2005;35:2193-214.

77. Ntoumanis N. A self-determination approach to the understanding of motivation in physical education. Br J Educ Psychol 2001;71(Pt 2):225-42.

78. Murcia J, Gimeno E, Camacho A. Measuring self-determination motivation in a physical fitness setting: validation of the Behavioral Regulation in Exercise Questionnaire-2 (BREQ-2) in a Spanish sample. J Sports Med Phys 2007:47:366-78.

79. Baard PP, Deci EL, Ryan RM. Intrinsic need satisfaction: a motivational basis of performance and well-being in two work settings. J Appl Soc Psychol 2004;34:2045-68.

80. Brouwer KC, Rusch ML, Weeks JR, et al. Spatial epidemiology of HIV among injection drug users in Tijuana, Mexico. Ann Assoc Amer Geog 2012;102:1190-9.

81. Cooper HL, des Jarlais D, Ross Z, et al. Spatial access to syringe exchange programs and pharmacies selling over-the-counter syringes as predictors of drug injector's use of sterile syringes. Am J Public Health 2011;101:118-25.

82. Hoffman RE, Henderson N, O'Keefe K, et al. Occupational exposure to human immunodeficiency virus (HIV)-infected blood in Denver, Colorado, police officers. Am J Epidemiol 1994;139:910-17.
83. Brown CA, Lilford RJ. The stepped wedge trial design: a systematic review. BMC Med Res Methodol 2006;8:54.

84. Robertson A, Garfein R, Wagner KD, et al. Evaluating the impact of Mexico's drug policy reforms on people who inject drugs in Tijuana, B.C., Mexico, and San Diego, CA, United States: a binational mixed methods research agenda. Harm Reduct $J$ 2014;11:4.

85. Strathdee SA, Hallett TB, Bobrova N, et al. HIV and risk environment for injecting drug users: the past, present, and future. Lancet 2010;376:268-84.

86. Singer MC, Erickson PI, Badiane L, et al. Syndemics, sex and the city: understanding sexually transmitted diseases in social and cultural context. Soc Sci Med 2006;63:2010-21.

87. Auerbach JD, Caceres CF, Parkhurst JO. Addressing social drivers of HIV/AIDS for the long-term response: conceptual and methodological consideration. Global Public Health 2011;6(suppl 3): S293-309.

88. Ogden J, Gupta GR, Warner A, et al. Revolutionising the AIDS response. Global Public Health 2011;6(Suppl 3):S383-95.

89. Beyrer C, Malinowska-Sempruch K, Kamarulzaman A, et al. Time to act: a call for comprehensive responses to HIV in people who use drugs. Lancet 2010;376:551-63.

90. Rhodes T, Singer M, Bourgois $P$, et al. The social structural production of HIV risk among injecting drug users. Soc Sci Med 2005;61:1026-44.

91. Degenhardt L, Mathers B, Vickerman $\mathrm{P}$, et al. Prevention of HIV infection for people who inject drugs: why individual, structural, and combination approaches are needed. Lancet Infect Dis 2010;376:285-301.

92. Bernays $\mathrm{S}$, Rhodes T, Barnett T. Hope: a new way to look at the HIV epidemic. AIDS 2007;21(Suppl 5):S5-11.

93. Strathdee SA, Lozada R, Ojeda VD, et al. Differential effects of migration and deportation on HIV infection among male and female injection drug users in Tijuana, Mexico. PLOS ONE 2008;3:e2690.

94. Strathdee SA, Lozada R, Pollini RA, et al. Individual, social, and environmental influences associated with HIV infection among injection drug users in Tijuana, Mexico. J Acquir Immune Defic Syndr 2008;47:369-76.

95. Werb D, Vera A, Arredondo J, et al. Approaches to improving adherence to prevention interventions. International AIDS Conference. Melbourne, Australia: Drug Alcohol Depend, 2014.

96. Miller $\mathrm{CL}$, Firestone $\mathrm{M}$, Ramos R, et al. Injecting drug users experiences of policing practices in two Mexican-U.S. border cities: public health perspectives. Int J Drug Policy 2008;19:324-31.

97. Moreno JG, Licea JA, Ajenjo CR. Tackling HIV and drug addiction in Mexico. Lancet 2010;376:493-5.

98. Amon JJ. The political epidemiology of HIV. J Int AIDS Soc 2014;17:19327. 